\title{
Attachment to God in a collectivistic context and its impact on perceived stress
}

\author{
Syeda Saniya Zehra ${ }^{a}$, Elizabeth Schwaiger ${ }^{b}$ \\ ${ }^{a}$ MS(c), Clinical Psychology, Forman Christian College, Lahore, Pakistan \\ ${ }^{b}$ PsyD, Assistant Professor, Department of Psychology, Forman Christian College, Lahore, Pakistan
}

\begin{abstract}
Introduction: Research indicates that attachment to God is correlated with parental attachment and perceived stress. However, these relationships have not been studied outside the Western context. The present research evaluated the relationship between attachment to God and attachment to parents within different family systems and the impact of these attachments on perceived stress.
\end{abstract}

Methods: A sample of 284 Christian undergraduate students in Pakistan was surveyed. The data were collected from the participants through convenience sampling. Relationships between attachment to parents, attachment to God, religiosity, and perceived stress were studied.

Results: A significant positive relationship between attachment to parents and to God was found for the nuclear family system on the anxiety subscale. For the avoidance subscale, both nuclear and joint family systems had significant positive relationships between parental attachment and attachment to God; however, it was stronger for joint family systems. The multiple regression analysis showed parental avoidance $(B=$ $.256, p<.001)$ and God anxiety $(B=.281, p<.001)$ as the strongest predictors of stress. Discussion: The findings highlight the impact of collectivistic cultural values, particularly the importance of relationships. The implications include the significance of the impact of culture on attachment relationships and the finding that attachment correlates with lower levels of perceived stress. The research also shows the difference in attachment styles depending upon the family system the participant belongs to which can again be attributed to cultural norms and values.

Key Words: Attachment, family system, perceived stress, collectivistic culture, religiosity, Pakistan

\section{Introduction}

Hofstede described the dimension of collectivism and individualism as "the degree to which people in a society are integrated into a group." A greater focus on individual goals leads to bonds between extended family members becoming weaker whereas a greater focus on group goals and relational harmony strengthens those bonds. In 
many individualistic cultures, the nuclear family is preferred and in collectivistic nations such as Pakistan, the extended or joint family system is the family structure of choice. However, in an increasingly globalized world, there have been changes in family structures that are adapted to increase personal mobility. ${ }^{2,4}$ Families which have been based on collectivistic cultures ${ }^{1}$, such as Pakistan, are now being influenced by globalization and becoming more individualistic; small nuclear families are emerging as popular. The nuclear family system, which is more common in individualistic cultures such as the United States, can be explained as a structure where two generations, that is parents and their children, are living together. In a joint family system, husband, wife, and children are living with parents of either. In Pakistan, this is usually with the husband's parents. ${ }^{1}$ Nuclear family structures allow for the independence to move with changing global trends. On the other hand, these smaller structures have led to increased stress, loneliness, and economic hardships. ${ }^{1,4}$

Adoption of the nuclear family system and its alleged pertinence for economic growth has led to the disintegration of traditional extended/joint family systems in Asian countries. ${ }^{3}$ This is evidenced by research that has shown rates of joint family system membership as low as $50 \% .^{5}$ This shift in family structure may also signal a shift from the traditional focus on relational harmony and group membership to more individual goals and identity. ${ }^{2}$ Nevertheless, relationships or interpersonal attachments will no doubt continue to be important. Attachment relationship, even in Western contexts, is known to impact many facets of life, including religiosity, the way a person views God, and even the amount of perceived stress a person experiences. ${ }^{6,8,9}$

The rationale of the current research is to analyze how a religion, which is usually viewed through the westernized lens, is experienced by nonWestern citizens. In Pakistan, Christians constitute a minority population, and research has shown how religion and ethnicity can become identity markers for these groups. ${ }^{7}$ The current research examines how attachment relationships might be affected by non-Western, collectivistic, cultural values in a minority group.

\section{Attachment to God and Family Relationships}

Bowlby $^{6,8}$ and Ainsworth ${ }^{9}$ defined attachment as an emotional and psychological bond with a significant other. Attachment is a way to describe a relationship. In the context of family and parental attachment, attachment can be operationalized as the lasting bond, closeness, and security that children may or may not feel towards their parents. Similarly, attachment to God can be used as a way to define a person's relationship to God which is an excellent framework for the way Christians would describe their faith. ${ }^{10}$

Attachment theory proposes two broad categories of attachment styles, secure and insecure. $^{6,8,9}$ Ainsworth $^{9}$ explained the different styles of attachment in respect to the "Strange Situation" experiment. The purpose was to observe the behavior of children upon being separated from their primary caregiver. Ainsworth ${ }^{9}$ observed patterns of secure attachment and insecure attachment in terms of separation anxiety and avoidance. Avoidant and anxious attachment are categorized as insecure attachment styles. Fraley et $a l .{ }^{24}$ operationalized anxious/anxiety attachment as one where the absence of the attachment figure inculcates worry in an individual. This is derived from the concept of "separation anxiety" proposed by Bowlby ${ }^{6,8}$ whereupon being separated from their mothers, infants experienced distress and became anxious as the attachment figure was absent. Whereas avoidance attachment style is whereupon re-emergence of the attachment figure, the individual does not exhibit any clinging behavior resulting from the separation; ${ }^{9}$ instead, the behavior can be described as turning away.

Research has shown how the attachment relationship to parents is directly related to the attachment relationship to God through two main 
hypotheses, correspondence and compensation. According to the correspondence hypothesis, earlier attachment relationships form the basis for the dynamics of future relationships, such as that with God. The assumptions of the correspondence hypothesis can be linked to Bowlby's internal working models concept. ${ }^{6,8}$ The compensation hypothesis is based upon Ainsworth's substitute figures, where individuals may seek out attachment to God through an inverse relationship. ${ }^{9}$ That is, in cases where individuals experienced insecure attachment in childhood with their parents, they later have an experience of secure attachment with God. ${ }^{11,12,13}$

Attachment relationship to God, therefore, serves as a "secure base" for individuals, allowing them to explore the environment. ${ }^{12,13,14}$ Moreover, in cases where children face insecure attachment relationships during their childhood with their caregivers, they are likely to develop a more secure attachment to God, as God becomes the substitutionary caregiver. $^{12}$ This relationship between parental attachment and attachment to God has been explored in individualistic cultures. However, little is known about the impact of joint family systems on attachment to God.

\section{The Predictive Validity of Parental}

\section{Attachment, Attachment to God, Religiosity, and Family System on Perceived Stress}

It has been proposed that the bond that a child has with his/her caregiver impacts not only the development of different aspects of the individual's life, ${ }^{6,8,10}$ but also levels of stress. ${ }^{15}$ This theory of attachment can explain how attachment to God helps to mitigate stress and provides for emotional stability in one's life. A secure attachment to significant figures such as parents and God can help to buffer stress as this attachment relationship acts as a shield that helps in stressful situations. ${ }^{15,16}$ It has been observed that factors such as attachment to God and religiosity are significant predictors of perceived stress, both with regard to attachment style and level of religiosity. Depending upon these two factors, how individuals manage stress or perceived stress can be analyzed. ${ }^{17,18}$ Research on attachment styles and attachment to God has shown that avoidant attachment relationship to God is one of the strongest predictors of perceived stress. Attachment to God has also been demonstrated as an adequate predictor of psychological well-being in comparison to other measures such as that of image of God. ${ }^{19}$

Religiosity is one of the factors that help individuals cope with stressful situations. Religiousness can be regarded as pertinent to predicting growth of individuals when they face stressful situations. ${ }^{20}$ Religiosity holds the power to cultivate the negative and positive outcomes of stress, thus, helping to improve the functionality of an individual. Anger can be a negative outcome related to stress, due to lack of control of the situation; religiosity minimized this anger. Positive outcomes like having confidence in solving one's problems are maximized in times of stress if one has higher levels of religiosity. ${ }^{21}$

There is a dearth of research on the predictive value of nuclear and joint family systems on levels of perceived stress; however, higher levels of resilience, positive emotion, and social adjustment have been observed in adolescents from joint family systems $^{22}$ as well as lower levels of family dysfunction and higher social competence. ${ }^{23}$ Moreover, levels of life satisfaction have been found to be higher in Pakistanis from joint family systems. ${ }^{5}$ Given these findings and their relationship to perceived stress, it is possible that the family system will also be a predictor of perceived stress.

\section{Hypotheses}

1. The relationship between attachment to parents and attachment to God will be different in joint versus nuclear family systems.

2. After controlling for other demographic variables, attachment to parents, attachment to God, religiosity, and family system will predict levels of perceived stress. 


\section{Methods}

For this study, secondary analysis was performed on a dataset taken from an undergraduate research thesis. The initial study used a crosssectional research design to measure and evaluate the relationships between attachment to parents, attachment to God, religiosity, and perceived stress. The current study analyzed the correspondence hypothesis of attachment in the context of joint versus nuclear family systems, and the impact of attachment to parents, attachment to God, religiosity, and family system on perceived stress.

\section{Participants}

The participants in this study were 300 Christian students enrolled in various undergraduate study programs at a university in Lahore, Pakistan. Participation in the study was voluntary and no incentives were given. The participants had to sign the informed consent before proceeding with the questionnaire. Of the 300 students who voluntarily participated, 13 did not complete all the questions in the booklet and were, therefore, excluded, while 3 more were excluded due to outliers (Mahalanobis distances $<.001$; i.e., scores greater than 3.5 standard deviations from the mean). Descriptive statistics of the demographics of the remaining 284 participants can be found in Table 1.

Table 1. Descriptive statistics of the demographics of the sample

\begin{tabular}{lccc}
\hline Variables & Frequency $(n)$ & Percentage & $M(S D)$ \\
\hline Sex & & & \\
$\quad$ Male & 163 & $57.4 \%$ & \\
Female & 121 & $42.6 \%$ & \\
& & & \\
Age & - & - & 20.81 \\
& & & $(1.68)$ \\
Year of education & & & \\
$\quad$ Freshman & 103 & $36.3 \%$ & \\
$\quad$ Sophomore & 72 & $25.4 \%$ & \\
$\quad$ Junior & 55 & $19.4 \%$ & \\
$\quad$ Senior & 54 & $19 \%$ & \\
& & & \\
Family system & & $67.3 \%$ & \\
$\quad$ Nuclear family & 191 & $32.7 \%$ & \\
$\quad$ Joint family & 93 & & \\
\hline
\end{tabular}

\section{Measurement Tools}

Attachment to Parents (Experiences in Close Relationships; ECR-RS)

The Experiences in Close RelationshipsRelationship Structures Questionnaire (ECR$\mathrm{RS})^{24}$ was used to measure the participants' attachment relationships to parents which measures the two attachment styles, avoidance and anxious attachment. Two subscales of the instrument were employed, that is mother and father subscales, with 10 items each. The internal consistency reported for the subscales is desirable, mother anxiety $(\alpha=.88)^{24}$, mother avoidance $(\alpha=.92)^{24}$, father anxiety $(\alpha=.90)^{24}$, and father avoidance $(\alpha=.90) .{ }^{24}$ The responses were recorded on a 7-point Likert-type scale. For the present study the reliability was adequate as well, mother anxiety $(\alpha=.78)$, mother avoidance $(\alpha=.74)$, father anxiety $(\alpha=$ $.77)$, and father avoidance $(\alpha=.72)$.

\section{Attachment to God (Attachment to God}

\section{Inventory; $A G I)$}

The Attachment to God Inventory (AGI) ${ }^{10}$ was used to measure the individuals' attachment relationship towards God in terms of avoidance and anxiety. The scale consisted of 28 items, with an equal number of questions measuring avoidance $(\alpha=.84)^{10}$ and anxiety $(\alpha=.80)^{10}$ on a 7-point Likert-type scale. Both the subscales AGI avoidance $(\alpha=.79)$ and AGI anxiety $(\alpha=$ .77) had good reliability values in the present study.

\section{Religiosity (The Centrality of Religiosity Scale)}

To measure the variable of religiosity, the 10-item version of "The Centrality of Religiosity Scale" (CRS-10) was used. ${ }^{25}$ The scale measures religiosity on five dimensions, "intellect, ideology, public practice, private 
practice, and religious experience" where two questions evaluate each dimension. The responses are recorded on 5-, 6-, and 8-point Likert-type scales. The scale has good reliability $(\alpha=0.89$ to 0.94$){ }^{25}$ For the current study, the reliability of the scale was good as well $(\alpha=.77)$.

\section{Perceived Stress (Perceived Stress Scale)}

For measuring perceived stress, the 4-item version of the Perceived Stress Scale (PSS) was employed. ${ }^{26}$ The scale records responses on 5point Likert-type scale. The reliability of the scale was desirable in reference to previous research $(\alpha=.72){ }^{26}$ However, when there are four or fewer items on a scale, Cronbach's alpha has not been considered as a satisfactory indicator of reliability as it does not depict the scale's “internal structure." Hence, substitute measures should be considered. ${ }^{26}$ An alternate method for measuring reliability in this case was using the mean inter-item correlations. The mean inter-item correlations value was .24 which was in accordance with the desired value. $^{28}$

\section{Procedure and Ethical Considerations}

This study was approved by the Institutional Review Board of FC College (IRB219/02-2020). All participation in the study was voluntary and informed consent was obtained from the participants containing the details about participants' rights and purpose of the study. The data collected was confidential and only the principle and secondary author had access to it. Participants' anonymity was maintained as no identifying data was collected. There were no ethical breaches during the course of data collection. Given the sensitive nature of the topic of religion in Pakistan, convenience sampling was utilized as only
Christians could be approached to participate. The primary researcher recruited the participants through visiting Christian classes and groups on campus prior to the advent of the pandemic (over 3 weeks from $24^{\text {th }}$ February, 2020 to $13^{\text {th }}$ March, 2020). Each participant was asked to participate given their status as a Christian, and, though no incentives were offered, most of the students approached, agreed to participate.

\section{Data Analysis}

SPSS Version 25 was used to analyze the data. For hypothesis 1, correlations were converted to z-scores to compare students from joint and nuclear family systems on the relationship between attachment to parents and attachment to God. For hypothesis 2, multiple regression was used to evaluate the impact of attachment to parents, attachment to God, religiosity, and family system on perceived stress.

\section{Results}

\section{Descriptive Statistics}

Descriptive statistics of the study variables are displayed in Table 2.

Table 2:.Descriptive Statistics of the Study Variables

\begin{tabular}{lcc}
\hline Variables & $N(\%)$ & Mean $(S D)$ \\
\hline Family system & & \\
Joint & $93(32.7)$ & - \\
Nuclear & $191(67.3)$ & - \\
Attachment & & \\
ECR-RS Anxiety & $12.31(7.50)$ \\
ECR-RS Avoidance & $38.61(10.50)$ \\
AGI Anxiety & $50.87(13.60)$ \\
AGI Avoidance & $36.27(12.70)$ \\
Religiosity & $41.37(6.38)$ \\
Perceived Stress & $7.72(3.00)$ \\
\hline
\end{tabular}

Note. ECR-RS = The Experiences in Close RelationshipsRelationship Structures Questionnaire; AGI = Attachment to God Inventory. 


\section{Inferential Statistics}

Table 3. Correlation coefficients among study variables

\begin{tabular}{lcccccc}
\hline \multicolumn{1}{c}{ Variable } & 1 & 2 & 3 & 4 & 5 & 6 \\
\hline 1. ECR-RS Anxiety (Log 10) & & & & & \\
2. ECR-RS Avoidance & $.491^{* *}$ & & & & \\
3. AGI Anxiety & $.232^{* *}$ & .064 & & & \\
4. AGI Avoidance & $.317^{* *}$ & $.323^{* *}$ & .117 & & & \\
5. CRS (Log 10) & $.181^{* *}$ & $.189^{* *}$ & .109 & $.452^{* *}$ & & \\
6. Family System & .027 & .077 & $-.153^{* *}$ & -.002 & -.018 & \\
7. PSS & $.174^{* *}$ & $.265^{* *}$ & $.301^{* *}$ & $.128^{*}$ & .072 & -.073 \\
\hline
\end{tabular}

Note. ${ }^{*}$ ECR-RS $=$ The Experiences in Close Relationships - Relationship Structures Questionnaire; AGI = Attachment to God Inventory; CRS $=$ Centrality of Religiosity Scale; PSS $=$ Perceived Stress Scale.

*Significant at the $p<.05$ level. **Significant at the $p<.01$ level.

The bivariate correlations showed that ECRRS anxiety and avoidance subscale have a significant positive relationship $(r=.491, p<.01$; see Table 3$)$, this can be attributed to the fact that both avoidance and anxiety attachment stem from insecure attachment with primary caregivers. Furthermore, the relationship between God anxiety and parental anxiety is positive $(r=.232, p<.01)$, and so is the correlation between God avoidance and parental avoidance $(r=.323, \mathrm{p}<.01)$, which can be attributed to correspondence hypothesis. Religiosity on the other hand has an insignificant positive relationship with parental anxiety, parental avoidance, God anxiety, and God avoidance. On the other hand, the family system to which a participant belongs has a negative relationship with God anxiety $(r=-.153, p$
$<.01)$. This finding has been further been discussed in Table 4. The variable of perceived stress also has a positive relationship with parental anxiety, parental avoidance, God anxiety, and God avoidance. This finding suggests a positive relationship between perceived stress and attachment to parents and God, which is further explored in a regression analysis (see table 5).

\section{Hypothesis 1}

To test the first hypothesis, the file was split into two groups (joint and nuclear family systems), and then correlations were computed (see Table 4), transformed to z-scores, and compared between joint and nuclear family systems.

Table 4. Correlation coefficients between Attachment to God and Attachment to Parents across joint and nuclear family systems.

\begin{tabular}{lcccc}
\hline \multicolumn{1}{c}{ Variable } & \multicolumn{2}{c}{ Juclear } & ECR-RS Anxiety & ECR-RS Avoid \\
\hline AGI Anxiety & ECR-RS Anxiety & ECR-RS Avoid & .094 & $.430^{* *}$ \\
AGI Avoid & $.329^{* *}$ & $.282^{* *}$ & & E
\end{tabular}

Note. ECR-RS = The Experiences in Close Relationships - Relationship Structures Questionnaire; AGI = Attachment to God Inventory; Avoid $=$ Avoidance. ${ }^{* *}$ Significant at the $p<.01$ level.

The difference between joint and nuclear family systems on the anxiety subscale was significant $(z=1.95 ; p=.05)$, thereby showing that, for participants from nuclear family systems there was a moderate positive relationship $(r=.329)$ between attachment to parents and attachment to
God, while this relationship vanished for joint family system $(r=.094)$. However, for the avoidance subscale, the difference between joint and nuclear family systems was not statistically significant $(z=-$ $1.35 ; p>.05)$. 


\section{Hypothesis 2}

For the second hypothesis, a simple regression analysis was computed to analyze the predictive value of the study variables (parental attachment, God Attachment, religiosity, family system) on perceived stress. Pre-analysis screening indicated no violations of the assumptions of multicollinearity or singularity (see Table 4 for correlation values). Three cases were excluded due to outliers, and two scales were transformed to improve normality (Parental Anxiety [Log10] and Religiosity [InverseLog10]).

Table 5.Results of Regression Analysis: Impact of Study Variables on Perceived Stress

\begin{tabular}{|c|c|c|c|c|c|c|c|c|}
\hline \multirow[b]{2}{*}{ Variables } & \multirow{2}{*}{$\begin{array}{c}\begin{array}{c}\text { Unstandardized } \\
\text { coefficients }\end{array} \\
\mathrm{B}\end{array}$} & \multicolumn{2}{|c|}{$\begin{array}{c}\text { Standardized } \\
\text { coefficients }\end{array}$} & \multirow[b]{2}{*}{$t$} & \multirow[b]{2}{*}{$\mathrm{R}$} & \multirow[b]{2}{*}{$R^{2}$} & \multirow[b]{2}{*}{$\underset{R^{2}}{\text { adj. }}$} & \multirow[b]{2}{*}{$\begin{array}{l}\text { Semi partia } \\
\text { correlations }\end{array}$} \\
\hline & & $B$ & $P$ & & & & & \\
\hline 1. (Constant) & 2.771 & & .189 & $\begin{array}{c}1.31 \\
7\end{array}$ & $\begin{array}{c}.39 \\
3\end{array}$ & $\begin{array}{c}.15 \\
4\end{array}$ & .136 & \\
\hline $\begin{array}{l}\text { ECR-RS } \\
\text { Avoidance }\end{array}$ & .073 & .256 & $<.001$ & $\begin{array}{c}3.91 \\
0\end{array}$ & & & & .230 \\
\hline $\begin{array}{l}\text { ECR-RS Anx } \\
(\log 10)\end{array}$ & -.277 & -.021 & .747 & -.322 & & & & -.019 \\
\hline AGI Avoidance & .006 & .026 & .688 & .402 & & & & .024 \\
\hline AGI Anxiety & .062 & .281 & $<.001$ & $\begin{array}{c}4.82 \\
5\end{array}$ & & & & .280 \\
\hline CRS $(\log 10)$ & -.404 & -.016 & .800 & -.254 & & & & -.015 \\
\hline Family System & -.314 & -.049 & .383 & -.873 & & & & -.053 \\
\hline
\end{tabular}

The results of the multiple regression were significant $[F(6,274)=8.341, p>.001]$ with an $R 2$ of .136. The strongest predictors being parental avoidance $(\beta=.256, p<.001)$ and God anxiety $(\beta=$ $.281, p<.001$; see Table 5).

\section{Discussion}

The current study sought to investigate the correspondence hypothesis in light of joint versus nuclear family systems. Additionally, the study evaluated the impact that attachment to parents, attachment to God, religiosity, and family system have on perceived stress. It was found that the relationship between anxious attachment to God and anxious attachment to parents was strongest for nuclear family systems and followed the correspondence hypothesis, but not for joint family systems. Avoidant attachment to God was weakly related to avoidant attachment to parents in nuclear family system, but not in joint family system.
No difference was found between parental avoidance and God avoidance attachment, for both the family systems. Thus, the assumptions of correspondence hypothesis appear to be applicable to both family systems. However, the correlation between parental avoidance attachment and God avoidance is greater for joint family system in comparison to nuclear family system. This is supported by the response of people in a collectivist culture to conflict. Leung et al., ${ }^{29}$ demonstrated how countries practicing collectivist culture opt for ways that promote harmony and social cohesion and not confrontation. This implicitly promotes avoidance in important attachments. ${ }^{29}$ It may be that the cultural imperative to avoid conflict is stronger than the influence of adapting to a more westernized nuclear family system.

For the anxiety attachment subscale, the attachment relationship between parents and God vanishes for the joint family system. The correspondence theory can, thus, be held for nuclear 
family system participants but not for joint family system. This can possibly be due to the presence of caregivers other than parents, for instance grandparents. An important relationship with a nonparent caretaker might well alter attachment relationships with parents. ${ }^{30,31}$ This possibility in a joint family system can thus account for such findings. Another attachment relationship may take precedence and be correspondent with attachment to God. It is also possible that in a joint family system, with the presence of many different possible caregivers, the view of an individual about the world of attachment relationships may be more fluid. When one attachment figure is not available, there are others to take his/her place.

The compensatory hypothesis was not tested here, and this can be considered as a guideline for future research studies. One reason for these findings may be the way in which the information about primary caregivers was associated with parents only, where the attachment relationship with God might have correspondence with other caregivers/relations, for instance: grandparents, uncles, or aunts. On the other hand, in nuclear family systems the correspondence hypothesis ${ }^{11}$ can help explain the relationship between parental attachment and God attachment on the basis of anxiety subscale due to a clear identification of caregivers, that is, parents as blueprint for authority figures such as God.

In the current study, anxious attachment to God was the stronger predictor of perceived stress, which is inconsistent with the findings of the previous research which showed avoidant attachment to God as the stronger predictor of perceived stress or mental health. ${ }^{18,32}$ However, the previous research did show anxious attachment to God as having a negative relationship with mental health, which is consistent with the findings of the current study. This variation in results can be attributed to cultural or religious factors like the image of God, as suggested by Leman et al. ${ }^{18}$ the Wrathful God image had a weak but a positive correlation with mental health. Paul and Nadiruzzaman's ${ }^{33}$ analysis of research on the 2004 Indian Ocean Tsunami showed how the two religious groups, Muslims and Christians, mainly regarded the natural disaster as a punishment sent from God. Such interpretations of events can be helpful in explaining the anxious attachment to God as the predictor of stress.

Another predictor of stress was parental avoidance. As discussed earlier, avoidance-related behavior is a key component of collectivist cultures. ${ }^{1}$ Cultural customs almost shun the idea of confronting individuals if any issue arises, especially with those in authority such as parents. This is consistent with supporting how avoidance attachment in a parental context can be regarded as a predictor of perceived stress amongst the Pakistani population.

This study did not find any predictive relationship between religiosity or family system and perceived stress. The fact that levels of religiosity do not predict perceived stress in this group may be related to the religious context of Pakistan where Christians are a minority. It may be that this minority status somehow mitigates the relationship between religiosity and perceived stress. Research projects on levels of religiosity and perceived stress are generally conducted on majority groups whose religious affiliations have few repercussions in their lives.

The finding that family system is not a significant predictor of perceived stress was also unexpected. Previous research in Pakistan suggests that family system has a significant impact on levels of resilience, positive emotion, social adjustment, ${ }^{21}$ family functioning, social competence, ${ }^{22}$ and life satisfaction. ${ }^{5}$ It is possible that family system is not a significant predictor because of the population under study or that the individual-collective dimension may not be the best way to characterize it. Stress that is mediated by the family system when an individual is in university may be different than in other populations. Moreover, it is possible that there are many other variables that impact stress in the life 
of a university student, thereby reducing the mediating effect of family system on levels of stress.

\section{Implications}

The finding that the correspondence hypothesis did not appear to explain anxious attachment to parents and anxious attachment to God for the joint family system provides a strong indication for the importance of joint family systems in mitigating anxious attachment. This can be seen as a strength of collectivistic cultures. Perhaps in a joint family system, the presence of increased number of family members allows for substitute attachment figures such as grandparents. ${ }^{30,31}$ The joint family system may provide an opportunity for multiple attachment relationships and, therefore, greater fluidity in future attachments, particularly the attachment to God. The idea of parental attachment as a blueprint ${ }^{6,8,9}$ for other attachment relationships may not hold true in collectivistic cultures where there are multiple close caregivers.

The finding that parental avoidance is a significant predictor of stress can provide clarity in planning therapeutic interventions. This finding further elaborates the importance of relational harmony and group membership in collectivistic cultures. ${ }^{1}$ Strategies to improve and provide for mental health facilities for young adults, especially those who identify with minority groups, should consider the nature of family relationships and impact of avoidance as a tool for reducing relational tension within collectivistic cultures.

Anxious attachment to God was found to be one of the most significant predictors of stress. These findings help to explain how attachment to God serves as an important factor for mitigating stress when the study population belongs to the minority group living in a collectivist society. This also provides evidence for the need to train pastors and laypeople in assisting their congregants to build a less anxious relationship with God. The nature of this relationship provides either a buffer against or an impetus for greater stress.

\section{Limitations and Future Directions}

A factor that might account for these findings is the level of parental religiosity. Since level of parental religiosity can correspond to children's level of religiosity, it can, therefore, influence how strong or weak the attachment relationship to God is. This variable should be evaluated in future research studies.

The birth order of the participants was not taken into account. This might have contributed to the correlations between parental and God attachment relationships. For instance, the difference in attention and closeness with parents that the participants might have experienced starting from their childhood, as a result of birth order. ${ }^{34,35}$ In relation to this factor, the number of siblings the individuals of this study have might have also been a factor contributing towards the correlations. It can be explained in terms of how parents with fewer children are able to give them time, attentions, and the proximity they require. This might not be possible in cases in which there is a greater number of children in a family, and this might lead to less parental proximity and closeness, thereby, explaining the parental attachment relationship correlations. Similarly, the gender of the siblings might also contribute towards their parental attachment to either of the parents. ${ }^{34,36}$

The compensatory hypothesis should also be studied in reference to variables of the current research. The compensatory hypothesis describes the inverse relationship between attachment to parents and attachment to God. For example, if the attachment relationship with parents is avoidant and anxious, such as in the case of abuse, the attachment relationship with God often shows a compensatory shift, such that God becomes a substitutionary figure. The attachment with God is therefore surprisingly healthy or "secure." Future researchers should consider examining the relationship more closely. 
Finally, the findings of this research suggest that further research is needed to ascertain whether minority status, religion, or the collectivistic culture play a role in determining the course of attachment. For example, a comparative analysis between Muslims and Christians can be used to study whether the attachment relationship between parents and God is a product of culture or religion.

\section{References}

1. Hofstede G. Dimensionalizing cultures: the Hofstede Model in context [Internet]. Online Read Psych Culture. 2011;2(1). https://doi.org/10.9707/23070919.1014

2. Rahman K, Zhang D. Globalization and family values: eroding trends. Int J Soc Admin Sci. 2017;2(2):63-74. https://doi.org/10.18488/journal.136.2017.22.63.74

3. Alam A. Factors and consequences of nuclearization of family at Hayatabad Phase-II, Peshawar. Sarhad J Agr. 2008;24(3):555-9. Available from: https://agris.fao.org/agrissearch/search.do?recordID=PK2010000020

4. Rahman $\mathrm{S}$, Uddin $\mathrm{S}$. The impact of globalization on family values. Int J Adv Res. 2017;5(8):968-77. https://doi.org/10.21474/ijar01/5143

5. Saqib Lodhi F, Ahmed Khan A, Raza O, Uz Zaman T, Farooq U, Holakouie-Naieni K. Level of satisfaction and its predictors among joint and nuclear family systems in District Abbottabad, Pakistan. Med J Islam Repub Iran. 2019;33(59). https://doi.org/10.47176/mjiri.33.59

6. Bowlby J. Attachment and loss: Vol. 1: Attachment. 2nd ed. New York: Basic Books; 1982/1969

7. Phinney J, Line AL. Ethnic identity in college students from four ethnic groups. J Adolescence. 1990;13(2):171-83. https://doi:10.1016/01401971(90)90006-s

8. Bowlby J. Attachment and loss: Vol. 2: Separation. 2nd ed. New York: Basic Books; 1973.

9. Ainsworth MD. Attachments across the life span. Bull NY Acad Med. 1985 Nov;61(9):792-812. PMID: 3864511; PMCID: PMC1911889. Available from: https://www.ncbi.nlm.nih.gov/pmc/articles/PMC1911 $\underline{889 / \text { ?page }=1}$

10. Beck R, McDonald A. Attachment to God: the Attachment to God Inventory, tests of working model correspondence, and an exploration of faith group differences. J Psychol Theol. 2004;32(2):92-103. https://doi.org/10.1177/009164710403200202

11. Brown B, Bakken J. Parenting and peer relationships: reinvigorating research on family-peer linkages in adolescence. J Res Adolescence. 2011;21(1):153-65. https://doi.org/10.1111/j.1532-7795.2010.00720.x

12. Granqvist P. religiousness and perceived childhood attachment: on the question of compensation or correspondence. J Sci Stud Relig. 1998;37(2):350-67. https://doi.org/10.2307/1387533

13. Dickie J, Eshleman A, Merasco D, Shepard A, Wilt M, Johnson M. Parent-child relationships and children's images of god. J Sci Stu Relig. 1997;36(1):25-43. https://doi.org/10.2307/1387880

14. Berk LE. Emotional and Social Development in Infancy and Toddlerhood. In: Infants and Children. 5th ed. Boston: Pearson Education, Inc, Allyn, Bacon; 2005. p.264-77.

15. Rabbani M, Kasmaienezhadfard S, Pourrajab M. The relationship between parental attachment and stress: a review of literatures related to stress among students. Online J Counsel Educ. 2014;3(1):42-50. Available from:

https://www.researchgate.net/profile/Masoumeh_Pour rajab2/publication/263773206_The Relationship_bet ween_Parental_Attachment_and_Stress_A_Review_o f_Literatures_Related to Stress_among_Students/lin ks/55b1a65b08aed621ddfd59e7/The-Relationshipbetween-Parental-Attachment-and-Stress-A-Reviewof-Literatures-Related-to-Stress-among-Students.pdf

16. Rowatt W, Kirkpatrick L. Two dimensions of attachment to god and their relation to affect, religiosity, and personality constructs. J Sci Stud Relig. 2002;41(4):637-51. https://doi.org/10.1111/1468-5906.00143

17. Reiner S, Anderson T, Hall M, Hall T. Adult attachment, god attachment and gender in relation to perceived stress. J Psychol Theol. 2010;38(3):175-85. https://doi.org/10.1177/009164711003800302

18. Ellison C, Bradshaw M, Kuyel N, Marcum J. Attachment to god, stressful life events, and changes in psychological distress. Rev Relig Res. 2011;53(4):493-511. https://doi.org/10.1007/s13644011-0023-4

19. Leman J, Hunter W, Fergus T, Rowatt W. Secure attachment to god uniquely linked to psychological 
health in a national, random sample of American adults. Int J Psychol Rel. 2018;28(3):162-73. https://doi.org/10.1080/10508619.2018.1477401

20. Park C. Religiousness and religious coping as determinants of stress-related growth. Arch Psychol Relig. 2006;28(1):287-302. https://doi.org/10.1163/008467206777832517

21. Merrill R, Read C, LeCheminant A. The influence of religiosity on positive and negative outcomes associated with stress among college students. Ment Heal, Relig Culture. 2009;12(5):501-11. https://doi.org/10.1080/13674670902774106

22. Sahar N, Muzaffar N. Role of family system, positive emotions and resilience in social adjustment among Pakistani adolescents. J Educ, Health Comm Psych. 2017;6(2):46-58. Available from: https://media.neliti.com/media/publications/135843EN-role-of-family-system-positive-emotions.pdf

23. Saleem T, Gul S. Family dysfunctioning and social competence in adolescents: a comparative study of family structure. Pakistan J Physiol. 2016;12(3):1922. Available from: http://www.pps.org.pk/PJP/123/Tamkeen.pdf

24. Fraley R, Heffernan M, Vicary A, Brumbaugh C. The experiences in close relationships-Relationship Structures Questionnaire: a method for assessing attachment orientations across relationships. Psychol Assessment. 2011;23(3):615-25. https://doi.org/10.1037/a0022898

25. Huber S, Huber O. The Centrality of Religiosity Scale (CRS). Religions. 2012;3(3):710-24. https://doi.org/10.3390/rel3030710

26. Cohen S, Kamarck T, Mermelstein R. a global measure of perceived stress. J Health Soc Behav. 1983;24(4):385-96. https://doi.org/10.2307/2136404

27. Crutzen R, Peters G. Scale quality: alpha is an inadequate estimate and factor-analytic evidence is needed first of all. Health Psychol Rev. 2015;11(3):242-47. https://doi.org/10.1080/17437199.2015.1124240
28. Pallant J. SPSS survival manual: A step by step guide to data analysis using SPSS for Windows (version12). Maidenhead: Open University Press; 2005.

29. Leung K, Au Y, Fernández-Dols J, Iwawaki S. Preference for methods of conflict processing in two collectivist cultures. Int J Psychol. 1992;27(2):195209. https://doi.org/10.1080/00207599208246875

30. Poehlmann J. An attachment perspective on grandparents raising their very young grandchildren: implications for intervention and research. Inf Mental Health J. 2003;24(2):149-73. https://doi.org/10.1002/imhj.10047

31. Sun Y, Jiang N. The effect of grandparents' coparenting on young children's personality and adaptation: Chinese three-generation-families. Asian Soc Sci. 2017;13(5):7-15. https://doi.org/10.5539/ass.v13n5p7

32. Wei M, Ku T, Chen H, Wade N, Liao K, Guo G. Chinese Christians in America: attachment to God, stress, and well-being. Couns Values. 2012;57(2):16280. https://doi:10.1002/j.2161-007x.2012.00015.x

33. Paul B, Nadiruzzaman M. religious interpretations for the causes of the 2004 Indian Ocean Tsunami. Asian Profile. 2013;41(1): 67-76. Available from: https:/www.researchgate.net/publication/298192349 Religious_Interpretations_for_the_Causes_of_the_20 04 Indian Ocean Tsunami

34. Suneel I, Schwaiger Suneel E, Anthony S. Attachment styles and their demographic correlates among adult children of alcoholic fathers in Pakistan. Pakistan Armed Forces Med J. [Forthcoming].

35. Salmon C. Birth order and relationships. Human Nature. 2003;14(1):73-88. https://doi.org/10.1007/s12110-003-1017-x

36. van IJzendoorn M, Moran G, Belsky J, Pederson D, Bakermans-Kranenburg M, Kneppers K. The similarity of siblings' attachments to their mother. Child Devel. 2000;71(4):1086-98. https://doi.org/10.1111/1467-8624.00211

Peer Reviewed: Submitted 30 Mar 2021, accepted 9 Dec 2021, published 27 Dec 2021

Competing Interests: None declared.

December 2021. Christian Journal for Global Health 8(2) 
Acknowledgements: The authors would like to acknowledge the Christian students who took part in this study. Without them, it would not have been possible. There was no funding for this research. All tools used in this study are publicly available for research purposes and authors were additionally contacted to confirm permission for the use of the scales for the Attachment to God Inventory (AGI). ${ }^{10}$

Correspondence: Syeda Saniya Zehra, Lahore, Pakistan. saniyazehra1707@gmail.com

Cite this article as: Zehra SS, Schwaiger E. Attachment to God in a collectivistic context and its impact on perceived stress. Christ J Global Health. Dec 2021;8(2):24-35.

https://doi.org/10.15566/cjgh.v8i2.531

(C) Authors. This is an open-access article distributed under the terms of the Creative Commons Attribution License, which permits unrestricted use, distribution, and reproduction in any medium, provided the original author and source are properly cited. To view a copy of the license, visit http://creativecommons.org/licenses/by/4.0/ 